\title{
Clinical significance of perioperative EMT-CTCs in rectal cancer patients receiving open/laparoscopic surgery
}

\author{
W. YIN ${ }^{1, *}$, Y. M. HAN ${ }^{2,3, *}$, Z. L. LI ${ }^{2}$, Z. X. HUANG ${ }^{2}$, L. HUANG ${ }^{2}$, X. G. ZHONG ${ }^{2, *}$ \\ ${ }^{1}$ Department of Pathology, The People's Hospital of Guangxi Zhuang Autonomous Region, Nanning 530021, Guangxi, China; ${ }^{2}$ Department of \\ General Surgery, The People's Hospital of Guangxi Zhuang Autonomous Region, Nanning 530021, Guangxi, China; ${ }^{3}$ Department of General \\ Surgery, The First People's Hospital of Xuzhou, Xuzhou, Jiangsu, China
}

*Correspondence: xiaogangzhong@163.com

Received July 9, 2019 / Accepted October 8, 2019

\begin{abstract}
The objective of this study was to explore the clinical significance of perioperative CTCs (circulating tumor cells) counts and EMT-CTCs (epithelial-mesenchymal transition-CTCs) in rectal cancer patients. A total of 30 patients with rectal cancer who underwent radical resection of rectal cancer at the Guangxi Zhuang Autonomous Region People's hospital were enrolled. Five $\mathrm{ml}$ peripheral blood was withdrawn from 30 patients with rectal cancer before the operation and seven days after the operation and at the corresponding time also from 20 healthy volunteers. CanPatrol ${ }^{\mathrm{mm}}$ CTC detection technique was used to enrich and identify CTCs and IER3 expression simultaneously. We found out that the preoperative total CTCs were correlated with lymph node metastasis $(\mathrm{p}=0.008)$ and tumor size, and mixed CTCs were closely correlated with lymph node metastasis $(\mathrm{p}=0.009)$. The number of IER3-positive total CTCs and mesenchymal CTCs were statistically associated with tumor size, $\mathrm{p}=0.034$ and 0.043 , respectively. The number of CTCs varied significantly before and after the operation in all patients $(\mathrm{p}=0.049)$. There were significant differences in CTCs variations between the open operation group and the laparoscopic operation group. In the laparoscopic operation group, the average number of single-cell CTCs was 6.9 before operation and 3.5 after the operation $(\mathrm{p}=0.013)$. In the open operation group, the average number of single-cell CTCs was 5.9 before operation and 4.2 after the operation. To conclude, surgery is associated with a decrease of CTCs in rectal cancer patients, especially in patients receiving laparoscopic surgery. The number of CTCs before the operation in rectal cancer patients is related to the size of tumors and regional lymph node metastasis. CTCs detection and characterization may be useful for clinical staging and lymph node dissection during operation.
\end{abstract}

Key words: rectal cancer, CTCs, EMT, open radical resection, laparoscopic radical resection

Colorectal cancer is the third most common malignant tumor worldwide and over $50 \%$ of all patients will ultimately develop relapse or metastatic diseases [1]. Currently, surgery is the preferred choice for the treatment of this disease. With the improvement of technology, laparoscopic surgery is getting more and more applications in many surgery domains [2]. Due to the considerations on costs and oncological safety, the development of laparoscopic surgery for rectal cancer is relatively slow compared to other abdominal solid tumors [3]. A large amount of clinical data has shown that the local relapse rates of both laparoscopic and open surgery for rectum cancer were $5 \%$, no statistically significant difference in 3-year disease-free survival (DFS) and overall survival (OS) between these two groups was observed $[4,5]$. However, several studies demonstrated that laparoscopy was inferior to open surgery in the positive margin and survival $[2,6,7]$. Therefore, more reference biomarkers are required to help to choose the appropriate mode of surgery for every patient.

Circulating Tumor Cells (CTCs) are rare tumor cells found in the peripheral blood of cancer patients, and the presence of CTCs is considered the "seeds" of metastatic disease that accounts for $90 \%$ of all cancer-related deaths [8]. Several studies were conducted in various types of cancers (breast, lung, colorectal, prostate, melanoma, etc.) and presenting CTCs have proven prognostic value in these cancer types [9-13]. Advanced colorectal patients with $5 \mathrm{CTCs} / 7.5 \mathrm{ml}$ or higher CTCs had a significantly worse survival than those in which CTCs were less than 5 [11]. In patients with non-metastatic colorectal cancers, the detection of CTCs was predictive for therapeutic effect and progression [14-18].

Epithelial-mesenchymal transition (EMT) is a cellular process in which cells lose their epithelial characteristics and acquire mesenchymal features [19]. EMT has been associated 
with various tumor functions, including tumor initiation, tumor cell migration, intravasation to the blood, resistance to therapy, and metastasis [20]. Studies of CTCs have identified significant heterogeneity of epithelial and mesenchymal marker expression, as well as the presence of biphenotypic cells that express markers of both cell lineages [21]. Increased mesenchymal marker expression correlated with triplenegative breast cancer and also was suggestive of therapeutic resistance [22]. However, few studies have focused on the EMT-CTC variations in rectal patients before and after the operation.

The immediate early response gene X-1 (IEX-1), also known as IER3, belongs to the family of the immediate early response genes [23]. Unlike other members of the family, IER3 lacks a DNA-binding domain and may function as a co-activator or co-repressor $[23,24]$. Differences in IER3 expression between tumor tissue and adjacent normal cells can be helpful in both the prognostic prediction and clinical management of cancer patients [25]. Current data suggest that the absence of IER3 expression was associated with poor prognosis in ovarian cancer [26], while positive expression of IER3 predicted progression in breast cancer and myeloma $[25,27]$. As in colorectal cancer, the prognostic prediction of IER3 expression remained controversial yet [25, 28, 29].

In this study, CanPatrol ${ }^{\mathrm{mw}}$ (Surexam, Guangzhou, China) technique [30] was used to identify perioperative CTC counts and CTC subpopulations in rectal patients receiving laparo-

Table 1. Characteristics of patients included in this study $(n=30)$.

\begin{tabular}{|c|c|c|c|}
\hline Factor & Subgroups & $\mathbf{n}$ & $\%$ \\
\hline \multirow[t]{2}{*}{ Age } & $<55$ & 10 & 33.3 \\
\hline & $\geq 55$ & 20 & 66.7 \\
\hline \multirow[t]{2}{*}{ Gender } & male & 22 & 73.3 \\
\hline & female & 8 & 26.7 \\
\hline Histology & adenocarcinoma & 30 & 100 \\
\hline Differentiation & moderate & 30 & 100 \\
\hline \multirow[t]{2}{*}{ T stage } & $2-3$ & 10 & 33.3 \\
\hline & 4 & 20 & 66.7 \\
\hline \multirow[t]{2}{*}{$\mathrm{N}$} & No & 12 & 40 \\
\hline & $\mathrm{N}+$ & 18 & 60 \\
\hline \multirow[t]{3}{*}{ TNM stage } & I & 4 & 13.3 \\
\hline & II & 8 & 26.7 \\
\hline & III & 18 & 60 \\
\hline \multirow[t]{2}{*}{ Tumor size } & $\leq 3 \mathrm{~cm}$ & 19 & 63.3 \\
\hline & $>3 \mathrm{~cm}$ & 11 & 36.7 \\
\hline \multirow[t]{2}{*}{ Vascular/perineural invasion } & yes & 8 & 26.7 \\
\hline & no & 22 & 73.3 \\
\hline \multirow[t]{2}{*}{ Type of surgery } & open & 15 & 50 \\
\hline & laparoscopy & 15 & 50 \\
\hline \multirow[t]{2}{*}{ Surgical margins } & negative & 30 & 100 \\
\hline & positive & 0 & 0 \\
\hline \multirow[t]{2}{*}{ CTCs } & negative & 2 & 6.7 \\
\hline & positive & 28 & 93.3 \\
\hline
\end{tabular}

CTCs - circulating tumor cells scopic/open surgery. We evaluated the relationship between CTCs, IER3 expression of CTCs, and characteristics of rectal patients, as well as CTC changes after surgery.

\section{Patients and methods}

Patients and healthy volunteers. Thirty patients with rectal cancer and 20 patients with benign diseases were consecutively enrolled between September 2016 and December 2017 at Gastrointestinal Surgery, the People's Hospital of Guangxi Zhuang Autonomous Region. All colon cancer patients received laparoscopic or open surgery. Peripheral blood specimens $(5 \mathrm{ml})$ for CTC analysis were withdrawn one day before surgery and 7 days after surgery. Healthy volunteers also collected $5 \mathrm{ml}$ peripheral blood at the corresponding time point. This study protocol was approved by the Institutional Ethics Committee, and written informed consent was obtained from all the patients.

CTC analysis. The enrichment and characterization of CTCs were conducted with CanPatrol ${ }^{\mathrm{Tx}}$ technique. In brief, CTCs from the blood samples were isolated and enriched by the filtration method through a calibrated membrane with 8 $\mu \mathrm{m}$ pores as previously described [30].

mRNA in situ hybridization (ISH). A tri-color ISH assay was conducted to identify and classify CTCs. Specific capture probes for epithelial markers included EpCAM, CK8, CK18, and CK19, while these for mesenchymal markers included Twist1 and Vimentin. A CD45 probe was used to identify leukocytes. After incubation with all three kinds of probes, cells on the membrane were stained with DAPI for another $5 \mathrm{~min}$ before analyzed with an automatic fluorescence microscope. The ISH results were further verified by qualified pathologists. Red fluorescence, green fluorescence, and bright white fluorescence indicated the expression of epithelial markers, mesenchymal markers, and leukocyte biomarker, respectively. Epithelial CTCs were characterized as red fluorescence-positive $\mathrm{CD}^{-} 5^{-} \mathrm{DAPI}^{+}$, while biphenotypic CTCs were characterized as red and green fluorescencepositive $\mathrm{CD}^{-} 5^{-} \mathrm{DAPI}^{+}$, mesenchymal CTCs were characterized as green fluorescence-positive $\mathrm{CD} 45^{-} \mathrm{DAPI}^{+}$. The expression of IER3 in each CTC was analyzed by mRNA-ISH using purple fluorescence as described above.

Follow-up analysis. Follow-up was performed by outpatient visit, telephone, or hospital stay. The first outpatient visit was performed one month after surgery. Serum tumor marker, CT, or MRI were performed for evaluation. The second and third outpatient visit was performed 3 months after surgery with routine blood tests, and 6 months after surgery with colonoscopy, respectively. The subsequent follow-up was conducted by telephone and outpatient visit, in turn, every 3 months. Postoperative treatment was performed if required. The latest follow-up time was May 1, 2019.

Statistical analysis. All data were analyzed using SPSS 23.0 software package (SPSS Inc., Chicago, IL, USA). Comparisons of CTCs between groups were assessed by non-param- 
eters tests. Spearman correlation test was used to evaluate the relations between clinicopathological features and IER3 expression. A chi-squared test was used for comparison between groups where appropriate. A p-value $<0.05$ on a two-sided level was considered statistically significant.

\section{Results}

Patient characteristics. A total of 30 rectal cancer patients ( 22 males, 8 females; median age 62 years, range $32-82$ years) were enrolled in this study. The basic characteristics of 30 rectal cancer patients are summarized in Table 1, including age, gender, histology, differentiation, TNM stage, tumor size, lymphatic metastasis, vascular/perineural invasion, types of surgery, and surgical margins.

Classification of CTCs. The CTCs were classified into three subpopulations according to the epithelial-to-mesenchymal transition (EMT) status by using multiplex RNA-ISH assay, including epithelial CTCs, mesenchymal CTCs, and biphenotypic epithelial/mesenchymal CTCs (Figure 1A). The results also showed that no CTC could be detected in healthy donors. Analysis of CTCs in all 30 patients with rectal cancer revealed that $93.3 \%$ were CTC-positive. The distribution of CTCs in each patient is summarized in Table S1.
Association between CTCs number, phenotypes, and patient pathological features. Next, we explored the correlations between CTC counts or EMT status and clinicopathological characteristics, as shown in Table 2. The total CTCs median of advanced stages (III) rectal cancer patients was higher than that of early stages (I+II) patients $(6.0 \mathrm{CTCs} / 5 \mathrm{ml}$ vs. $3.0 \mathrm{CTCs} / 5 \mathrm{ml} ; \mathrm{p}<0.05)$, indicating that higher total CTCs number was associated with advanced tumor stages (Figure 2A). Patients without lymph node metastasis presented lower total CTCs numbers, and biphenotypic CTCs compared with patients presenting lymph node metastasis (3.0 CTCs/5 ml vs. 6.0 CTCs/5 ml, p=0.006; 0.5 CTCs/5 ml vs. $3.5 \mathrm{CTCs} / 5 \mathrm{ml}, \mathrm{p}=0.004$, respectively, Figure $2 \mathrm{~B})$. Similarly, patients with smaller tumor size $(\leq 3 \mathrm{~cm})$ showed significantly lower total CTCs, biphenotypic CTCs, and mesenchymal CTCs than patients with tumor diameter over $3 \mathrm{~cm}$. In addition, younger patients $(<55 \mathrm{y})$ had higher total CTC counts than older patients $(6.5 \mathrm{CTCs} / 5 \mathrm{ml}$ vs. $3.5 \mathrm{CTCs} / 5 \mathrm{ml}$, $\mathrm{p}=0.019)$. The distribution of CTC counts or EMT-CTC status presented no significant difference in gender, $\mathrm{T}$ stage, vascular/perineural invasion or type of surgery.

The number of IER3-positive CTCs correlates with tumor size in rectal cancer. Total CTCs number was $\geq 1 \mathrm{CTC} / 5 \mathrm{ml}$ in 28 out of 30 rectal patients. We investigated
A

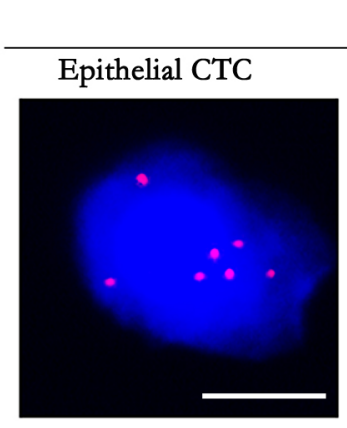

B
CTC phenotypes

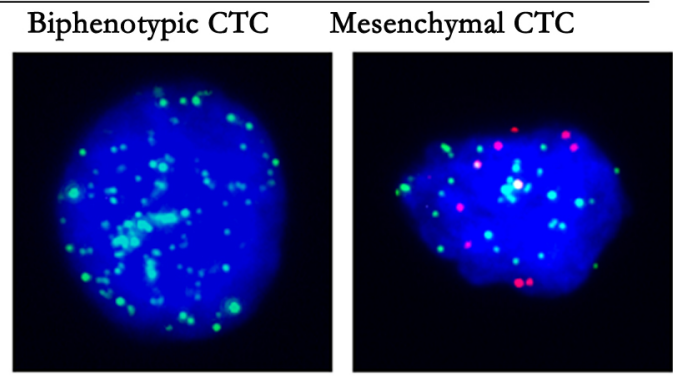

IER3 expression

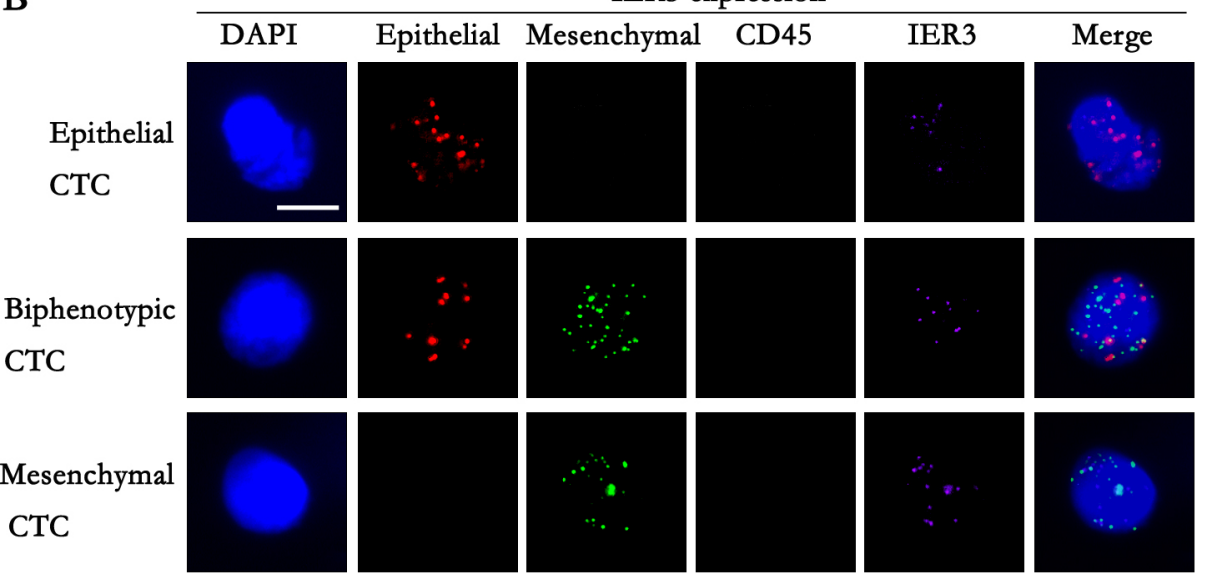

Figure 1. EMT phenotypes and IER3 expression of CTCs detected by the RNA in situ hybridization in rectal cancer patients. A) Fluorescence microscopy images of three types of CTCs with positive expression of epithelial markers (EpCAM and CK8/18/19, red dots), biphenotypic markers (red dots and green dots and mesenchymal markers (Vimentin and Twist, green dots). B) IER3 expression (Alexa Fluor 647) in the epithelial, hybrid, and mesenchymal CTCs. Scale bar $=10 \mu \mathrm{m}$. 
the expression of IER3 gene in CTCs from these 28 patients. The distribution of IER3 positive CTCs in each patient is summarized in Table S1. As shown in Table 3, the number of IER3-positive total CTCs and mesenchymal CTCs were statistically associated with tumor size, $\mathrm{p}=0.034$ and 0.043 , respectively. There was no significant relationship between the number of IER3-positive CTCs and clinicopatholog- ical variables of rectal cancer, including age, gender, type of surgery, TNM stage, and vascular/perineural invasion (Table 3).

CTC changes of different operative approaches. One half of 30 rectal patients received open surgery, while another half received laparoscopic surgery. As shown in Table S2, no significant difference in clinical parameters between the two
A

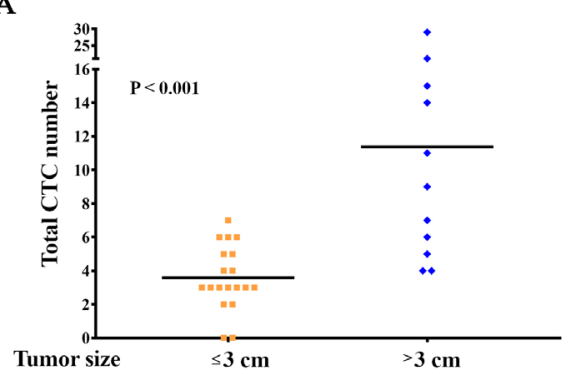

D

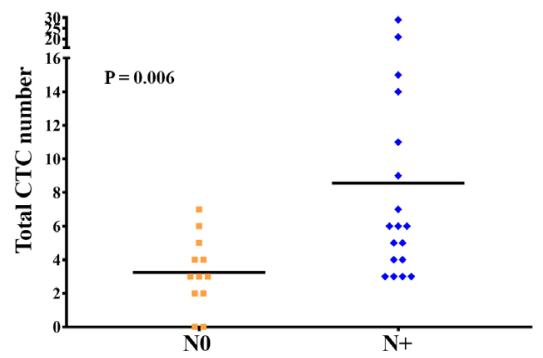

B

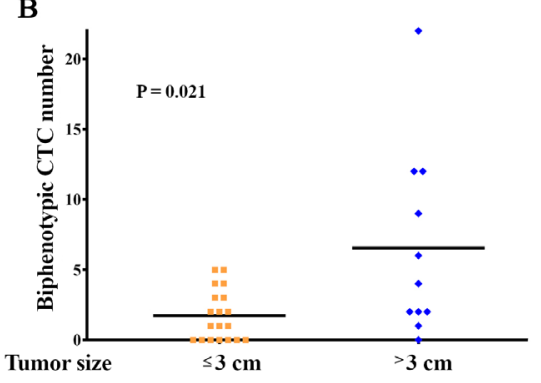

E

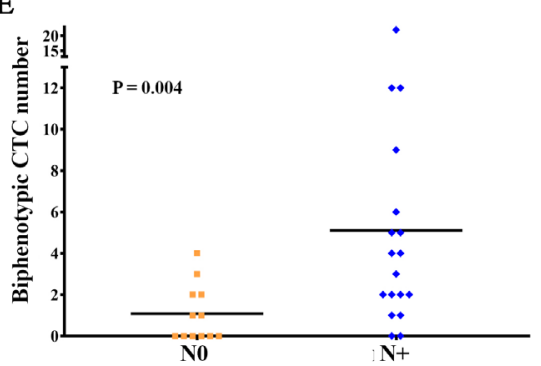

C

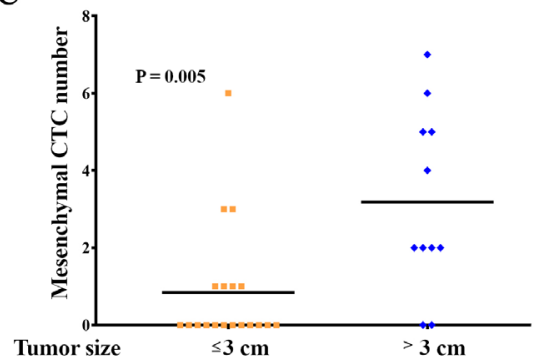

Figure 2. Correlation of CTCs/CTC subpopulations and clinical characteristics. A-C) the distribution of total CTCs, biphenotypic CTCs, and mesenchymal CTCs between patients with tumor size $\leq 3 \mathrm{~cm}$ and $>3 \mathrm{~cm}$, respectively. D and E) the distribution of total CTCs, and biphenotypic CTCs between patients with/without lymph node metastasis.

Table 2. Correlations between CTCs counts three types of CTCs and clinical data of rectal cancer patients ( $\mathrm{n}=30$ ).

\begin{tabular}{|c|c|c|c|c|c|c|c|c|c|c|}
\hline & & $\mathbf{n}$ & $\begin{array}{c}\text { Total CTCs } \\
\text { median }\end{array}$ & p-value & $\begin{array}{c}\text { Epithelial } \\
\text { CTCs median }\end{array}$ & p-value & $\begin{array}{l}\text { Biphenotypic } \\
\text { CTCs median }\end{array}$ & p-value & $\begin{array}{l}\text { Mesenchymal } \\
\text { CTCs median }\end{array}$ & p-value \\
\hline Factor & Subgroups & & & & & & & & & \\
\hline \multirow[t]{2}{*}{ Age } & $<55$ & 10 & 6.5 & 0.019 & 0.0 & 0.948 & 4.0 & 0.1 & 1.5 & 0.267 \\
\hline & $\geq 55$ & 20 & 3.5 & & 1.0 & & 1.5 & & 0.0 & \\
\hline \multirow[t]{2}{*}{ Gender } & male & 22 & 5.0 & 0.237 & 1.0 & 0.393 & 2.0 & 0.534 & 0.5 & 0.629 \\
\hline & female & 8 & 4.0 & & 0.0 & & 2.0 & & 1.0 & \\
\hline \multirow[t]{2}{*}{ T stage } & $2-3$ & 10 & 4.5 & 0.812 & 0.5 & 0.746 & 2.0 & 0.812 & 1.0 & 0.65 \\
\hline & 4 & 20 & 4.5 & & 1.0 & & 2.0 & & 0.5 & \\
\hline \multirow[t]{2}{*}{ Tumor size } & $\leq 3 \mathrm{~cm}$ & 19 & 3.0 & $<0.001$ & 0.0 & 0.35 & 1.0 & 0.021 & 0.0 & 0.005 \\
\hline & $>3 \mathrm{~cm}$ & 11 & 9.0 & & 1.0 & & 4.0 & & 2.0 & \\
\hline \multirow[t]{2}{*}{$\mathrm{N}$} & No & 12 & 3.0 & 0.006 & 1 & 0.692 & 0.5 & 0.004 & 0 & 0.134 \\
\hline & $\mathrm{N}+$ & 18 & 6.0 & & 0.5 & & 3.5 & & 1.5 & \\
\hline \multirow[t]{2}{*}{ TNM stage } & I- II & 12 & 3.0 & 0.006 & 1.0 & 0.692 & 0.5 & 0.004 & 0 & 0.134 \\
\hline & III & 18 & 6.0 & & 0.5 & & 3.5 & & 1.5 & \\
\hline \multirow[t]{2}{*}{$\begin{array}{l}\text { Vascular/perineural } \\
\text { invasion }\end{array}$} & yes & 8 & 4.5 & 0.696 & 0.0 & 0.534 & 3.5 & 0.277 & 1.0 & 0.765 \\
\hline & no & 22 & 4.5 & & 1.0 & & 2.0 & & 0.5 & \\
\hline \multirow[t]{2}{*}{ Types of surgery } & open & 15 & 3.0 & 0.137 & 1.0 & 0.87 & 1.0 & 0.015 & 0.0 & 0.744 \\
\hline & laparoscopy & 15 & 5.0 & & 1.0 & & 4.0 & & 1.0 & \\
\hline
\end{tabular}

$\mathrm{N}$ - lymph node; CTCs - circulating tumor cells; bold font means $\mathrm{p}<0.050$ 
Table 3. Correlations of IER3-positive total CTCs and three types of CTCs with clinical parameters.

\begin{tabular}{|c|c|c|c|c|c|}
\hline \multirow{2}{*}{ Characteristics } & \multirow{2}{*}{ Parameter } & \multicolumn{4}{|c|}{ IER3-positive CTC } \\
\hline & & Epithelial & Biphenotypic & Mesenchymal & Total \\
\hline Age & $\rho^{\mathrm{a}}$ & 0.232 & 0.004 & 0.137 & 0.183 \\
\hline$(\leq 55 />55)$ & $\mathrm{p}^{\mathrm{b}}$ & 0.217 & 0.982 & 0.470 & 0.332 \\
\hline Gender & $\rho$ & 0.206 & -0.145 & -0.083 & -0.067 \\
\hline (male / female) & $\mathrm{p}$ & 0.274 & 0.444 & 0.663 & 0.727 \\
\hline Type of surgery & $\rho$ & -0.073 & -0.153 & 0.177 & -0.067 \\
\hline (laparoscopy / open) & $\mathrm{p}$ & 0.701 & 0.419 & 0.35 & 0.726 \\
\hline Vascular/perineural invasion & $\rho$ & 0.066 & 0.036 & 0.070 & 0.023 \\
\hline (yes / no) & $\mathrm{p}$ & 0.731 & 0.852 & 0.713 & 0.902 \\
\hline Tumor size & $\rho$ & 0.021 & 0.232 & 0.388 & 0.372 \\
\hline$(\leq 3 \mathrm{~cm} />3 \mathrm{~cm})$ & $\mathrm{p}$ & 0.912 & 0.217 & 0.034 & 0.043 \\
\hline TNM stage & $\rho$ & 0.027 & -0.014 & 0.209 & 0.111 \\
\hline (I-II / III) & $\mathrm{p}$ & 0.889 & 0.939 & 0.267 & 0.561 \\
\hline T stage & $\rho$ & 0.213 & -0.017 & 0.251 & 0.231 \\
\hline$(2-3 / 4)$ & $\mathrm{p}$ & 0.258 & 0.931 & 0.181 & 0.220 \\
\hline $\mathrm{N}$ & $\rho$ & -0.009 & -0.026 & 0.090 & 0.048 \\
\hline$(\mathrm{N} 0 / \mathrm{N}+)$ & $\mathrm{p}$ & 0.961 & 0.893 & 0.637 & 0.802 \\
\hline
\end{tabular}

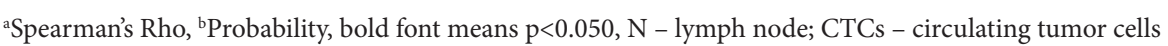

A

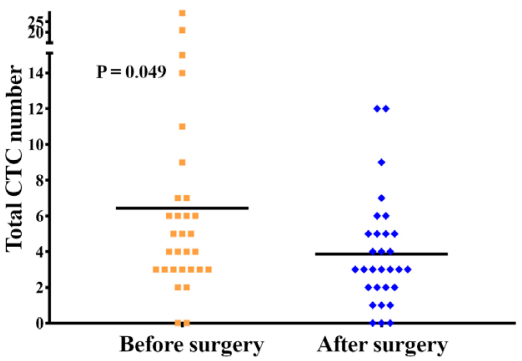

B

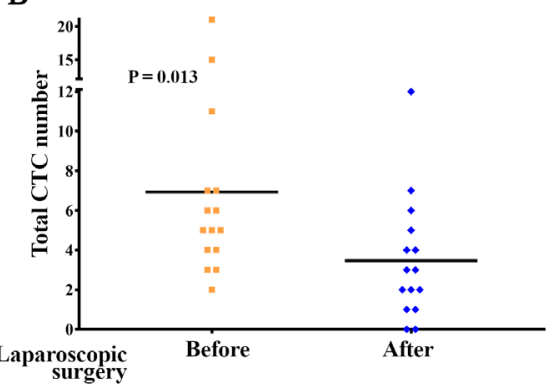

C

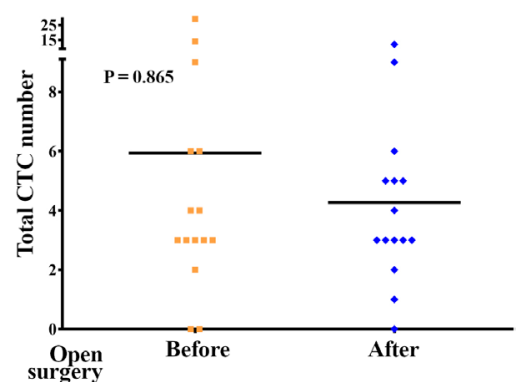

Figure 3. The distribution of total CTCs before and after surgery. A) the distribution of total CTCs in all patients before and after surgery. B and C) the distribution of total CTCs in patients received laparoscopic and open surgery, respectively.

groups was discovered. All 30 patients screened for CTC counts before and after surgery. A comparison of the preoperative and postoperative CTC counts is shown in Figure 3. The preoperative and postoperative CTC positive rates were 93.3\% and $90.0 \%$, respectively. Compared with preoperative CTC counts (mean 3.9 cells), the mean CTC counts after operation decreased significantly (mean 6.4 cells), $\mathrm{p}=0.049$, while no significant difference was discovered between preoperative and postoperative CTC subpopulations. In the laparoscopic surgery group, the mean preoperative CTC count was $6.9 \mathrm{CTCs} / 5 \mathrm{ml}$, and the mean postoperative CTC count was $3.5 \mathrm{CTCs} / 5 \mathrm{ml}, \mathrm{p}=0.013$. In the open surgery group, the mean preoperative CTC count was $5.9 \mathrm{CTCs} / 5 \mathrm{ml}$, and the mean postoperative CTC count was $4.2 \mathrm{CTCs} / 5 \mathrm{ml}$, $\mathrm{p}>0.05$. CTC subpopulations or IER3-positive CTCs at both time points showed no obvious difference in either mode of operation (open or laparoscopic).
Prognostic significance of perioperative CTCs changes. The latest follow-up time was May 1, 2019. The median follow-up time was 19.5 months (13-26 months). Fifty-nine patients were successfully followed up at regular intervals. One patient in the laparoscopic group was lost to follow up. Longer follow-up will be required to determine the prognostic significance of perioperative CTCs changes.

\section{Discussion}

Compared to traditional invasive approaches, such as tissue biopsy and molecular imaging, monitoring for CTCs is relatively noninvasive, requiring only a peripheral blood sample. CTCs are rare cells that are detached from primary tumors and metastatic deposits into the blood circulation. The acquisition of this invasive phenotype of tumors cells is hypothesized to correlate with EMT. During this process, 
tumor cells downregulate the expression of specific epithelial markers including EpCAM, E-cadherin, and cytokeratin, upregulate the expression of mesenchymal proteins such as vimentin and $\mathrm{N}$-cadherin, Twist, and so on [31]. After entering the bloodstream, CTCs can revert to the epithelial state through mesenchymal to epithelial transition (MET), implying the presence of a transition state between epithelial and mesenchymal [32]. These surface biomarkers are important for CTC identification and classification.

EpCAM-based CTCs enrichment and identification technique (CellSearch ${ }^{\mathrm{Tm}}$, Janssen Diagnostics, LLC, USA) has been widely used for clinical prognostic assessment of advanced cancer [9]. The dependence of CTC isolation on epithelial cell-specific technique may lead to an underestimation of the actual number of CTCs by missing tumor cells that underwent EMT [33-35]. CanPatrol ${ }^{m}$ technique is a combination of membrane filtration and epithelial/mesenchymal biomarkers-based identification and enables the isolation of CTCs with low/no epithelial markers possible.

In the present study, CTC counts, as well as biphenotypic CTCs were significantly related to the TNM stage and lymph node metastasis. It is consistent with previous reports showing that CTCs number positively correlate with stage $[18,36,37]$. These results support the idea of CTCs as a reference marker for preoperative staging and lymph node dissection. Interestingly, we found that younger patients had more CTC counts than older patients, indicating the role of CTCs in identifying high-risk patients.

Surgery remains an effective choice for rectal cancer patients. Our results showed that CTC counts in rectal cancer patients with TNM stage I-III decreased significantly after the operation, which is in line with previous findings in colorectal cancer and hepatocellular carcinoma $[17,38]$. However, other studies about hepatocellular carcinoma and squamous cell carcinoma of the head and neck reported the elevation of CTCs after surgery $[39,40]$. The discrepancy of these research results may possibly be due to the differences in CTC detection and time of blood sampling. In the laparoscopic surgery group, postoperative CTC counts decreased significantly comparing with preoperative CTC counts. Compared with open surgery, lower postoperatively CTC counts of laparoscopic surgery could be justified by the advantage of laparoscopy, including less blood loss, light pain, earlier return of bowel movement, and reduced length of hospital stay $[4,6]$. However, due to the relatively short follow-ups, the prognostic prediction of perioperative CTC counts and EMT-CTCs in rectal patients receiving laparoscopic/open surgery is currently impossible.

Furthermore, we analyzed the expression of IER3 in perioperative CTCs from rectal cancer patients for the first time. Previous studies showed that the expression of IER3 is distinct even in the same tumors with different disease stages [41]. The positive IER3 expression predicted good outcome and prognosis in the early stage of colorectal cancer patients [42]. Inconsistent with a previous report [41], we found that
IER3 expression in CTCs was only associated with tumor size. No significant correlations were observed between IER3 expression and other clinical parameters such as age, sex, TNM, lymph node metastasis, and mode of surgery. This discrepancy may be attributed to differences in sample size, technological issues or others. Additional larger sample studies with longer follow-ups to ascertain the clinical value of IER3 are warranted.

Taken together, our findings suggested both CTC counts and biphenotypic CTCs were significantly related to the TNM stage and lymph node metastasis, implying the potential value of CTCs and EMT-CTCs as a reference marker for preoperative staging and lymph node dissection. Furthermore, our study presented, for the first time, the perioperative CTC counts and EMT-CTCs between rectal patients receiving laparoscopic or open surgery. However, the main limitation of our study is the small sample size and short follow-ups, which might affect our results. Therefore, larger studies with adequate follow-ups are required for validating our results and drawing a convincing conclusion.

Supplementary information is available in the online version of the paper.

Acknowledgment: This research was financially supported by Guangxi medical and health technology research and development project fund and Guangxi health committee self-funded project.

\section{References}

[1] BRAY F, FERLAY J, SOERJOMATARAM I, SIEGEL RL, TORRE LA et al. Global cancer statistics 2018: GLOBOCAN estimates of incidence and mortality worldwide for 36 cancers in 185 countries. CA Cancer J Clin 2018; 68: 394-424. https://doi.org/10.3322/caac. 21492

[2] STEVENSON AR, SOLOMON MJ, LUMLEY JW, HEWETT P, CLOUSTON AD et al. Effect of laparoscopic-assisted resection vs open resection on pathological outcomes in rectal cancer: The ALaCaRT randomized clinical trial. JAMA 2015; 314: 1356-1363. https://doi.org/10.1001/jama.2015.12009

[3] ZHAO D, LI Y, WANG S, HUANG Z. Laparoscopic versus open surgery for rectal cancer: a meta-analysis of 3-year follow-up outcomes. Int J Colorectal Dis 2016; 31: 805-811. https://doi.org/10.1007/s00384-016-2506-9

[4] BONJER HJ, DEIJEN CL, ABIS GA, CUESTA MA, VAN DER PAS MH et al. A randomized trial of laparoscopic versus open surgery for rectal cancer. N Engl J Med 2015; 372: 1324-1332. https://doi.org/10.1056/NEJMoa1414882

[5] JEONG SY, PARK JW, NAM BH, KIM S, KANG SB et al. Open versus laparoscopic surgery for mid-rectal or low-rectal cancer after neoadjuvant chemoradiotherapy (COREAN trial): survival outcomes of an open-label, non-inferiority, randomised controlled trial. Lancet Oncol 2014; 15: 767774. https://doi.org/10.1016/S1470-2045(14)70205-0 
[6] FLESHMAN J, BRANDA M, SARGENT DJ, BOLLER AM, GEORGE V et al. Effect of laparoscopic-assisted resection vs open resection of stage II or III rectal cancer on pathologic outcomes: The ACOSOG Z6051 randomized clinical trial. JAMA 2015; 314: 1346-1355. https://doi.org/10.1001/ jama.2015.10529

[7] MARTINEZ-PEREZ A, CARRA MC, BRUNETTI F, DE'ANGELIS N. Pathologic Outcomes of Laparoscopic vs Open Mesorectal Excision for Rectal Cancer: A Systematic Review and Meta-analysis. JAMA Surg 2017; 152: e165665. https://doi.org/10.1001/jamasurg.2016.5665

[8] MAHESWARAN S, HABER DA. Circulating tumor cells: a window into cancer biology and metastasis. Curr Opin Genet Dev 2010; 20: 96-99. https://doi.org/10.1016/j. gde.2009.12.002

[9] HAYES DF, CRISTOFANILLI M, BUDD GT, ELLIS MJ, STOPECK A et al. Circulating tumor cells at each follow-up time point during therapy of metastatic breast cancer patients predict progression-free and overall survival. Clin Cancer Res 2006; 12: 4218-4224. https://doi.org/10.1158/1078-0432. CCR-05-2821

[10] DE BONO JS, SCHER HI, MONTGOMERY RB, PARKER C, MILLER MC et al. Circulating tumor cells predict survival benefit from treatment in metastatic castration-resistant prostate cancer. Clin Cancer Res 2008; 14: 6302-6309. https://doi.org/10.1158/1078-0432.CCR-08-0872

[11] COHEN SJ, PUNT CJ, IANNOTTI N, SAIDMAN BH, SABBATH KD et al. Relationship of circulating tumor cells to tumor response, progression-free survival, and overall survival in patients with metastatic colorectal cancer. J Clin Oncol 2008; 26: 3213-3221. https://doi.org/10.1200/ JCO.2007.15.8923

[12] MOON DH, LINDSAY DP, HONG S, WANG AZ. Clinical indications for, and the future of, circulating tumor cells. Adv Drug Deliv Rev 2018; 125: 143-150. https://doi. org/10.1016/j.addr.2018.04.002

[13] MORRIS RJ. Circulating tumor cells: quintessential precision oncology presenting challenges for biology. NPJ Precis Oncol 2017; 1: 16. https://doi.org/10.1038/s41698-017-0019-9

[14] BURZ C, POP VV, BUIGA R, DANIEL S, SAMASCA G et al. Circulating tumor cells in clinical research and monitoring patients with colorectal cancer. Oncotarget 2018; 9: 24561-24571. https://doi.org/10.18632/oncotarget.25337

[15] WANG W, WAN L, WU S, YANG J, ZHOU Y et al. Mesenchymal marker and LGR5 expression levels in circulating tumor cells correlate with colorectal cancer prognosis. Cell Oncol (Dordr) 2018; 41: 495-504. https://doi.org/10.1007/ s13402-018-0386-4

[16] WU F, ZHU J, MAO Y, LI X, HU B et al. Associations between the Epithelial-Mesenchymal Transition Phenotypes of Circulating Tumor Cells and the Clinicopathological Features of Patients with Colorectal Cancer. Dis Markers 2017; 2017: 9474532. https://doi.org/10.1155/2017/9474532

[17] YANG C, SHI D, WANG S, WEI C, ZHANG C et al. Prognostic value of pre- and post-operative circulating tumor cells detection in colorectal cancer patients treated with curative resection: a prospective cohort study based on ISET device. Cancer Manag Res 2018; 10: 4135-4144. https://doi. org/10.2147/CMAR.S176575
[18] ZHAO R, CAI Z, LI S, CHENG Y, GAO H et al. Expression and clinical relevance of epithelial and mesenchymal markers in circulating tumor cells from colorectal cancer. Oncotarget 2017; 8: 9293-9302. https://doi.org/10.18632/oncotarget.14065

[19] YE X, TAM WL, SHIBUE T, KAYGUSUZ Y, REINHARDT $F$ et al. Distinct EMT programs control normal mammary stem cells and tumour-initiating cells. Nature 2015; 525: 256-260. https://doi.org/10.1038/nature14897

[20] TSAI JH, YANG J. Epithelial-mesenchymal plasticity in carcinoma metastasis. Genes Dev 2013; 27: 2192-2206. https:// doi.org/10.1101/gad.225334.113

[21] JOLLY MK, BOARETO M, HUANG B, JIA D, LU M et al. Implications of the Hybrid Epithelial/Mesenchymal Phenotype in Metastasis. Front Oncol 2015; 5: 155. https://doi. org/10.3389/fonc.2015.00155

[22] YU M, BARDIA A, WITTNER BS, STOTT SL, SMAS ME et al. Circulating breast tumor cells exhibit dynamic changes in epithelial and mesenchymal composition. Science 2013; 339: 580-584. https://doi.org/10.1126/science. 1228522

[23] ARLT A, SCHAFER H. Role of the immediate early response 3 (IER3) gene in cellular stress response, inflammation and tumorigenesis. Eur J Cell Biol 2011; 90: 545-552. https://doi. org/10.1016/j.ejcb.2010.10.002

[24] ARLT A, ROSENSTIEL P, KRUSE ML, GROHMANN F, MINKENBERG J et al. IEX-1 directly interferes with RelA/ p65 dependent transactivation and regulation of apoptosis. Biochim Biophys Acta 2008; 1783: 941-952. https://doi. org/10.1016/j.bbamcr.2007.12.010

[25] WU MX, USTYUGOVA IV, HAN L, AKILOV OE. Immediate early response gene $\mathrm{X}-1$, a potential prognostic biomarker in cancers. Expert Opin Ther Targets 2013; 17: 593-606. https://doi.org/10.1517/14728222.2013.768234

[26] HAN L, GENG L, LIU X, SHI H, HE W et al. Clinical significance of IEX-1 expression in ovarian carcinoma. Ultrastruct Pathol 2011; 35: 260-266. https://doi.org/10.3109/01913123. 2011.608916

[27] YANG C, TRENT S, IONESCU-TIBA V, LAN L, SHIODA $\mathrm{T}$ et al. Identification of cyclin D1- and estrogen-regulated genes contributing to breast carcinogenesis and progression. Cancer Res 2006; 66: 11649-11658. https://doi. org/10.1158/0008-5472.CAN-06-1645

[28] NAMBIAR PR, NAKANISHI M, GUPTA R, CHEUNG E, FIROUZI A et al. Genetic signatures of high- and lowrisk aberrant crypt foci in a mouse model of sporadic colon cancer. Cancer Res 2004; 64: 6394-6401. https://doi. org/10.1158/0008-5472.CAN-04-0933

[29] USTYUGOVA IV, ZHI L, ABRAMOWITZ J, BIRNBAUMER L, WU MX. IEX-1 deficiency protects against colonic cancer. Mol Cancer Res 2012; 10: 760-767. https://doi. org/10.1158/1541-7786.MCR-11-0556

[30] WU S, LIU S, LIU Z, HUANG J, PU X et al. Classification of circulating tumor cells by epithelial-mesenchymal transition markers. PLoS One 2015; 10: e0123976. https://doi. org/10.1371/journal.pone.0123976 
[31] FRIEDLANDER TW, PREMASEKHARAN G, PARIS PL. Looking back, to the future of circulating tumor cells. Pharmacol Ther 2014; 142: 271-280. https://doi.org/10.1016/j. pharmthera.2013.12.011

[32] ARMSTRONG AJ, MARENGO MS, OLTEAN S, KEMENY G, BITTING RL et al. Circulating tumor cells from patients with advanced prostate and breast cancer display both epithelial and mesenchymal markers. Mol Cancer Res 2011; 9: 997-1007. https://doi.org/10.1158/1541-7786.MCR-10-0490

[33] DE WIT S, VAN DALUM G, LENFERINK AT, TIBBE AG, HILTERMANN TJ et al. The detection of $\operatorname{EpCAM(+)~and~}$ EpCAM(-) circulating tumor cells. Sci Rep 2015; 5: 12270. https://doi.org/10.1038/srep12270

[34] GORGES TM, TINHOFER I, DROSCH M, ROSE L, ZOLLNER TM et al. Circulating tumour cells escape from EpCAM-based detection due to epithelial-to-mesenchymal transition. BMC Cancer 2012; 12: 178. https://doi. org/10.1186/1471-2407-12-178

[35] ANDREE KC, VAN DALUM G, TERSTAPPEN LW. Challenges in circulating tumor cell detection by the CellSearch system. Mol Oncol 2016; 10: 395-407. https://doi. org/10.1016/j.molonc.2015.12.002

[36] SASTRE J, MAESTRO ML, PUENTE J, VEGANZONES S, ALFONSO R et al. Circulating tumor cells in colorectal cancer: correlation with clinical and pathological variables. Ann Oncol 2008; 19: 935-938. https://doi.org/10.1093/annonc/ mdm583

[37] TSAI WS, CHEN JS, SHAO HJ, WU JC, LAI JM et al. Circulating Tumor Cell Count Correlates with Colorectal Neoplasm Progression and Is a Prognostic Marker for Distant Metastasis in Non-Metastatic Patients. Sci Rep 2016; 6: 24517. https://doi.org/10.1038/srep24517
[38] SUN YF, XU Y, YANG XR, GUO W, ZHANG X et al. Circulating stem cell-like epithelial cell adhesion moleculepositive tumor cells indicate poor prognosis of hepatocellular carcinoma after curative resection. Hepatology 2013; 57: 1458-1468. https://doi.org/10.1002/hep.26151

[39] JATANA KR, BALASUBRAMANIAN P, MCMULLEN KP, LANG JC, TEKNOS TN et al. Effect of surgical intervention on circulating tumor cells in patients with squamous cell carcinoma of the head and neck using a negative enrichment technology. Head Neck 2016; 38: 1799-1803. https://doi. org/10.1002/hed.24519

[40] YU JJ, XIAO W, DONG SL, LIANG HF, ZHANG ZW et al. Effect of surgical liver resection on circulating tumor cells in patients with hepatocellular carcinoma. BMC Cancer 2018; 18: 835. https://doi.org/10.1186/s12885-018-4744-4

[41] SEGDITSAS S, SIEBER O, DEHERAGODA M, EAST $\mathrm{P}$, ROWAN A et al. Putative direct and indirect Wnt targets identified through consistent gene expression changes in APC-mutant intestinal adenomas from humans and mice. Hum Mol Genet 2008; 17: 3864-3875. https://doi. org/10.1093/hmg/ddn286

[42] SANCHEZ-CENIZO L, FORMENTINI L, ALDEA M, ORTEGA AD, GARCIA-HUERTA P et al. Up-regulation of the ATPase inhibitory factor 1 (IF1) of the mitochondrial H+-ATP synthase in human tumors mediates the metabolic shift of cancer cells to a Warburg phenotype. J Biol Chem 2010; 285: 25308-25313. https://doi.org/10.1074/jbc. M110.146480 